\title{
The Mysuru stUdies of Determinants of Health in Rural Adults (MUDHRA), India
}

\author{
Padukudru Anand Mahesh', Komarla Sundararaja Lokesh', Purnima Madhivanann ${ }^{2,3}$, \\ Sindaghatta Krishnarao Chaya', Biligere Siddaiah Jayaraj' ${ }^{1}$, Koustav Ganguly ${ }^{4}$, Murali Krishna ${ }^{5,6}$ \\ 'Department of Pulmonary Medicine, JSS Medical College and Hospital, JSS Academy of Higher Education and Research, Mysuru, India; \\ ${ }^{2}$ Department of Epidemiology, Florida International University, Miami, FL, USA; ${ }^{3}$ Public Health Research Institute of India, Mysuru, India; \\ ${ }^{4}$ Institute of Environmental Medicine, Karolinska Institutet, Stockholm, Sweden; ${ }^{5}$ Foundation for Research and Advocacy in Mental Health, \\ Mysuru, India; ${ }^{6}$ Faculty of Health and Social Care, Edgehill University, Lancashire, United Kingdom
}

\begin{abstract}
Between 2006 and 2010, in 16 randomly selected villages in rural areas of Mysore district, in south India, 8,457 subjects aged 30 and above were screened for symptoms of chronic respiratory disease. Of the 8,457 subjects, 1,692 were randomly invited for further evaluation of lung function and chronic obstructive pulmonary disease (COPD) by spirometry, and 1,085 of these subjects underwent lung function assessments for prevalent COPD and its risk factors. These 1,085 subjects, who were then aged between 35 and 80 years, constituted the Mysuru stUdies of Determinants of Health in Rural Adults (MUDHRA) cohort. Among other findings, threshold of biomass fuel smoke exposure suitable for use as a dichotomous risk factor for the diagnosis of chronic bronchitis was established, with a minimum biomass smoke exposure index of 60 found to be significantly associated with an elevated risk of developing chronic bronchitis. Five years later (between 2014 and 2016), 869 of the 1,085 participants were followed up with repeat lung function assessments for incident COPD and all-cause mortality. A subset of these participants $(\mathrm{n}=200)$ underwent blood tests for vitamin D levels, antioxidant activity, an assessment for anxiety and depression, and another subset $(\mathrm{n}=98)$ underwent a bioplex assay for 40 serum cytokines.
\end{abstract}

KEY WORDS: Lung diseases, Chronic obstructive pulmonary disease, Asthma, Spirometry, Biomass, Smoking

\section{INTRODUCTION}

Chronic obstructive pulmonary disease (COPD) is a major cause of the global burden of morbidity and mortality and is projected to be the third leading cause of death by 2030 [1-3]. Of the more than 170 million COPD patients worldwide, more than 3 million people died in 2015. COPD accounts for $2.6 \%$ of global disability-adjusted life years. The burden of COPD is particularly high in rural areas of

\section{Correspondence: Padukudru Anand Mahesh}

Department of Pulmonary Medicine, JSS Medical College and Hospital, M G Road, Fort Mohalla, Mysuru, Karnataka 570015, India Email:mahesh1971in@yahoo.com

Received: Apr 5, 2018 / Accepted: Jun 21, 2018 / Published: Jun 23, 2018

This article is available from: http://e-epih.org/

(C) This is an open-access article distributed under the terms of the Creative Commons Attribution License (http://creativecommons.org/licenses/by/4.0/), which permits unrestricted use, distribution, and reproduction in any medium, provided the original work is properly cited.

(C) 2018, Korean Society of Epidemiology low- and middle-income countries, and it is the second leading cause of death in India $[1,4,5]$ due to relatively high levels of smoking, ambient air pollution, exposure to biomass smoke, ozone, occupational particulate matter, and environmental tobacco smoke $[4,6]$. More than 3 billion people in the world are exposed to biomass smoke, compared to 1 billion smokers. We have shown previously that more than $90 \%$ of rural households used biomass fuels and that more than $50 \%$ of rural men smoked. Despite this, limited data exist on the prevalence of COPD and its burden in rural India [5].

In India, more than $70 \%$ of the population lives in rural areas [7]. The prevalence rates of COPD reported in population-based studies from rural India were not derived from standardised lung function assessments, but based on questionnaires [5,8-23]. Furthermore, in many studies, the participants were not randomly selected from the general population, which limits the generalizability of the findings. In those studies, the association of the dose of biomass smoke exposure with chronic respiratory disorders, particularly among non-smokers, was not examined. Those studies were primarily cross-sectional in design and were therefore limit- 
ed to reporting prevalent COPD, and participants were not followed up to estimate the incidence of chronic respiratory disorders [5,8-23]. Therefore, the Mysuru stUdies of Determinants of Health of Rural Adults (MUDHRA) cohort was established to address some of these limitations, and specifically to examine the risk factors for prevalent and incident COPD among rural men and women in southern India.

COPD is characterized by local and systemic inflammation involving various chemokines and cytokines, and the pulmonary inflammation extends into the systemic circulation [24-28]. In Indian COPD patients, pulmonary and systemic inflammation is due to exposure to important risk factors, such as tobacco smoking (usually in men) or biomass smoke exposure (usually in women). Exposure to these risk factors leads to increased levels of pro-inflammatory cytokines and reduced levels of anti-inflammatory and homeostatic cytokines. The interaction of various cytokines and chemokines is insufficiently understood, especially in biomass smoke-related COPD, and preliminary data have shown that biomass smoke-related COPD is different from tobacco smoke-related COPD [29]. Some cytokines are associated with increased inflammation in COPD (interleukin [IL]-6 and tumour necrosis factor alpha [TNF- $\alpha]$ ), the progression of disease (IL-2), or neutrophil recruitment (granulocyte-macrophage colony-stimulating factor, IL-8), whereas anti-inflammatory cytokines, such as IL-10, help to mitigate the inflammation. It is necessary to understand the cytokine signatures in COPD due to tobacco and biomass smoke, so a sub-sample of this cohort was evaluated to investigate differences in the cytokine signatures of tobacco smokerelated COPD and biomass smoke-related COPD.

\section{STUDY PARTICIPANTS}

Of the 7 taluks (sub-districts) in the district of Mysuru, 2 were randomly selected: rural Mysuru with 176 villages and Nanjangud with 131 villages. According to the 2001 Registrar General India census [7], each of these villages had 1,800-2,200 men and women



Figure 1. Map of India illustrating the site of sampling from which the Mysuru stUdies of Determinants of Health in Rural Adults (MUDHRA) cohort was set up (X depicts the 2 rural sub-districts selected for the study). above 30 years of age who were potentially eligible for recruitment. The sample size estimation indicated that we needed to screen at least 8,000 men and women aged above 30 years from these villages to obtain approximately 1,000 cases of symptomatic chronic chest disease. This estimation was based on an estimated COPD prevalence of $5 \%$ in this population, with $80 \%$ power and $10 \%$ standard error. Therefore, of the 307 villages, 8 villages from Mysuru and 8 villages from Nanjangud were randomly selected. Figure 1 shows a map of India illustrating the sampling sites from which the MUDHRA cohort was drawn.

Trained field workers conducted a door-to-door survey of all households $(n=3,139)$ from these 16 villages to identify those above 30 years of age. Houses were visited on at least 3 separate occasions before being declared non-responders $(n=196)$. Potentially eligible members from each household underwent a standardised structured interview adopted from the Burden of Obstructive Lung Diseases study [30]. This questionnaire was used to obtain information about socio-demographic variables, respiratory symptoms, self-reported diagnosis of respiratory disease and other non-

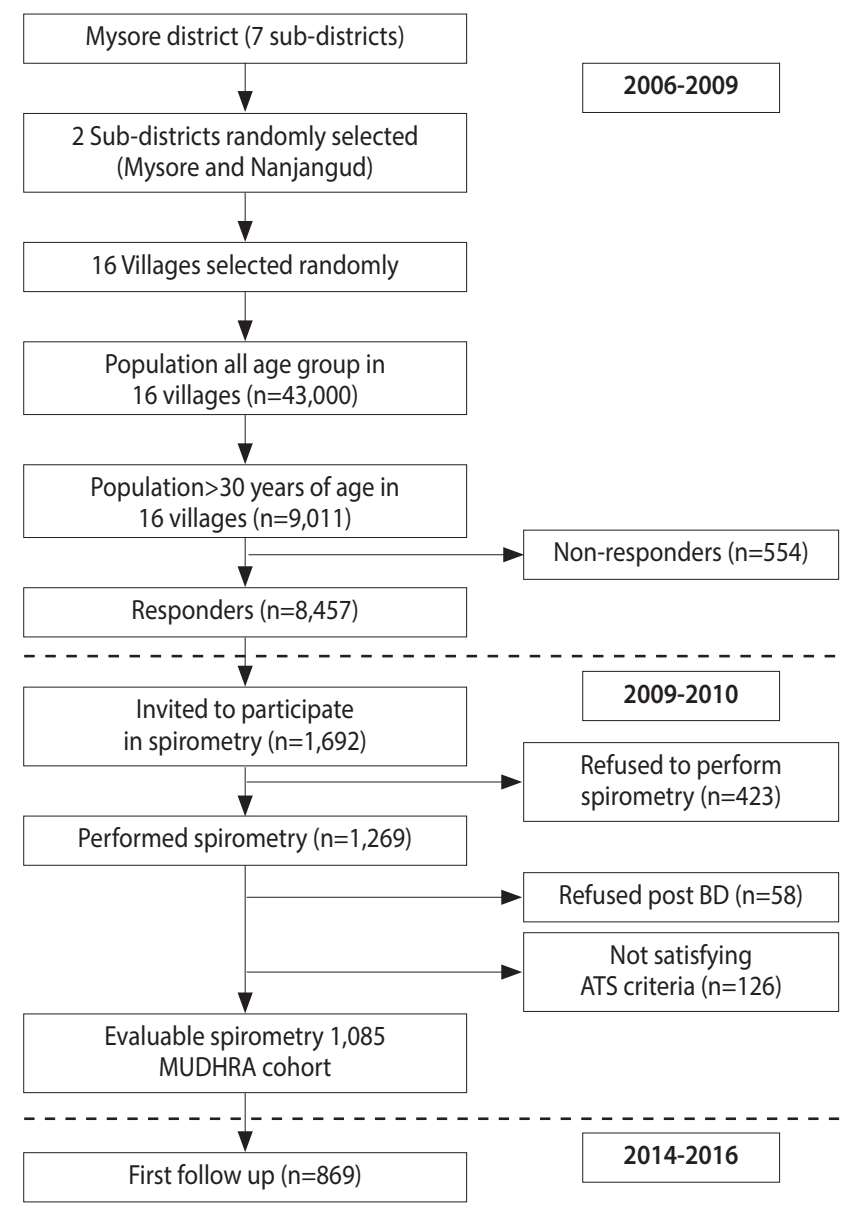

Figure 2. Flowchart for subject sampling and participation in different phases of the study. MUDHRA, Mysuru stUdies of Determinants of Health of Rural Adults; BD, broncho-dilator; ATS, American Thoracic Society. 
communicable diseases, medical history of consultations with a doctor or hospitalisation, and exposure to risk factors for chest disorders such as biomass fuel smoke and tobacco smoke.

In the first phase, a total of 8,457 subjects (women: $n=3,953$, 46.7\%; men: $\mathrm{n}=4,054,53.3 \%$ ) from 3,943 households were screened for symptoms of chronic respiratory diseases and the prevalence of chronic bronchitis. Data were also collected on socioeconomic status, education, occupation, tobacco and alcohol consumption, and biomass smoke exposure. Twenty percent $(n=1,692)$ of these subjects were randomly invited for further evaluation of lung function and COPD by spirometry. Among 1,692 subjects, 423 declined to participate (62 men and 361 women). More women and men refused to participate due to sociocultural issues. Of the 1,269 subjects who underwent spirometry, 1,085 satisfied the American Thoracic Society (ATS) standards [31]. Except for age and gender, other demographic characteristics were similar between the subjects who did and did not undergo spirometry. These 1,085 men and women constituted the MUDHRA cohort. Figure 2 depicts the flowchart for subject sampling and participation in different phases of the study.

After the baseline assessment for chronic lung disorders and their risk factors during 2006-2010, the cohort was retraced and examined 5 years later between 2014 and 2016. The follow-up evaluation of the cohort was conducted to establish the incidence rates of COPD, its predictors, and other chronic lung disorders. The baseline assessments were repeated and 869 subjects had acceptable spirometry results in the follow-up examination.

During this follow-up, a nested case-control design was used, and a subset of participants $(n=200 ; 100$ with COPD and 100 without) were evaluated further to examine the hypothesis that lower levels of vitamin D and oxidative stress markers and higher levels of depressive symptoms were associated with a greater decline in lung function (manuscript under preparation).

In a smaller subset of tobacco smokers with and without COPD $(n=50)$, we examined the serum levels of 8 cytokines. Later, in another subset of the cohort $(n=98)$, we examined the

Table 1. The list of variables collected during the different phases of the study

\begin{tabular}{|c|c|c|}
\hline Dataset & & Available data \\
\hline \multicolumn{3}{|l|}{ Baseline } \\
\hline Total $(n)$ & 8,457 & Demographics: age, sex, village, taluk \\
\hline Age (yr) & 30-105 & Socioeconomic indicators: education, occupation, type of house, number of people at home, number of room at home, \\
\hline Mean $\pm S D(y r)$ & $45.5 \pm 12.5$ & land ownership, vehicle ownership, type of latrine, source of drinking water, presence of indoor animals \\
\hline \multirow[t]{9}{*}{ Year } & 2006-2009 & Health related (respiratory symptoms) cough, phlegm, breathlessness, wheeze \\
\hline & & $\begin{array}{l}\text { Self-reported diagnosis of respiratory diseases: emphysema, asthma, allergic bronchitis, chronic bronchitis, COPD, lung } \\
\text { cancer, tuberculosis }\end{array}$ \\
\hline & & Self-reported diagnosis of non-communicable diseases: hypertension, diabetes mellitus, stroke, heart disease \\
\hline & & $\begin{array}{l}\text { Medical history of consultation with doctor or hospitalization: consulted or admitted for breathlessness, days of } \\
\text { hospitalization, chest surgeries, hospitalization in childhood for respiratory illness }\end{array}$ \\
\hline & & $\begin{array}{l}\text { Risk factors for chest disorders: tobacco smoking: type of smoking (beedi, cigarette, both), age of start, years of } \\
\text { smoking, frequency, current smoking status, pack years, smoking index }\end{array}$ \\
\hline & & Biomass fuel smoke exposure: years of exposure, hours exposed in a day, biomass index \\
\hline & & Environmental exposure to dust at work, tobacco smoke \\
\hline & & Type of fuel used for domestic work (kerosene, gas, biomass) presence of chimney and early life events \\
\hline & & $\begin{array}{l}\text { Knowledge and attitudes of smokers towards tobacco smoking and nicotine dependence: Fagerström } \\
\text { questionnaire (subset } n=900 \text { ) }[8,32]\end{array}$ \\
\hline \multicolumn{3}{|l|}{ MUDHRA cohort } \\
\hline Total (n) & 1,085 & Height, weight, body mass index \\
\hline Age (yr) & $35-80$ & Lung function: spirometry pre- and post-bronchodilator forced vital capacity, forced expiratory volume in the first \\
\hline Mean $\pm S D(y r)$ & $49.9 \pm 10.5$ & second \\
\hline Year & 2009-2010 & \\
\hline \multicolumn{3}{|l|}{ First follow up } \\
\hline Total $(n)$ & 869 & Respiratory symptom severity indicators: COPD Assessment Test [33], St. Georg's Respiratory Questionnaire [34], \\
\hline Age (yr) & 43-90 & modified Medical Research Council dyspnoea scale [35] \\
\hline Mean \pm SD (yr) & $60.7 \pm 12.9$ & Assessment of physical activity/exercise capacity: six-minute walk distance [36] \\
\hline \multirow[t]{5}{*}{ Year } & 2014-2016 & $\begin{array}{l}\text { Lung function test (spirometry) pre- and post-bronchodilator forced vital capacity, forced expiratory volume in the } \\
\text { first second }\end{array}$ \\
\hline & & Mental health: HAM-A [37] and HAM-D [38] scales \\
\hline & & Serum vitamin D levels $(n=200)$ \\
\hline & & Serum antioxidant reserves thiobarbituric acid reactive substances and ferric reducing antioxidant power $(n=200)$ \\
\hline & & Forty serum cytokines and chemokines ( $n=98)$ \\
\hline
\end{tabular}

SD, standard deviation; MUDHRA, Mysuru stUdies of Determinants of Health in Rural Adults; COPD, chronic obstructive pulmonary disease; HAM, Hamilton Anxiety and Depression. 
levels and interactions of 40 serum cytokines and chemokines using a multiplex immunoassay system in subjects with COPD related to tobacco smoking (men) and exposure to smoke from biomass fuels (women) compared to subjects exposed to similar levels of risk factors (tobacco smoking in men and biomass smoke exposure in women) but who had not developed COPD to assess whether the immune inflammatory signatures associated with tobacco smoking-related and biomass fuel exposure-related COPD were different (manuscript submitted) [39].

\section{MEASUREMENTS}

The demographic, socioeconomic, health-related, respiratory symptom-related, risk factors, spirometry, and lab variables measured during the different phases are listed in Table 1. Chronic bronchitis was defined as having cough with phlegm on most days for 3 months for at least 2 consecutive years [2]. COPD was defined according to the Global Initiative for Chronic Obstructive Lung Disease (GOLD) spirometry guidelines as a post-bronchodilator ratio of forced expiratory volume to forced lung capacity (FEV1/FVC) $<0.7$ [2], and asthma was defined according to the Global Initiative for Asthma spirometry guidelines as an increase of $12.0 \%$ and 200 $\mathrm{mL}$ in FEV1 on a post-bronchodilator spirometry test [40].

\section{KEY FINDINGS}

Of the 8,457 men and women screened for establishing this cohort, the prevalence of cough and phlegm for a 1-month duration was $14.3 \%$, that of chronic cough and phlegm (for 3 months' duration) was $8.4 \%$, and that of chronic bronchitis was $7.7 \%$. These conditions were all more common among the elderly, men, and current smokers [41-43].

A threshold of biomass fuel exposure for an elevated risk of the diagnosis of chronic bronchitis was established for the first time in a rural population. The biomass exposure index was first described by Behera \& Jindal [44], and was defined as the average hours of exposure to biomass smoke in a day multiplied by the number of years of exposure. We identified that a minimum biomass exposure index of 60 was necessary to have a significantly higher risk for developing chronic bronchitis than the general population. Increased exposure to biomass smoke increased the rates of chronic bronchitis in women [42]. Additional respiratory risk factors, such as an occupation involving contact with dust, were observed in $58.2 \%$ of subjects, and passive smoking was reported by $10.9 \%$.

Studies have shown that biomass smoke exposure is a significant factor rivalling tobacco smoke both for the development of COPD and for mortality associated with COPD $[45,46]$. Increased biomass smoke exposure was associated with increasing severity of airflow limitation and advanced COPD according to the GOLD criteria [47]. The importance of biomass smoke in COPD has been further confirmed by studies that have longitudinally evaluated the effect of switching over to cleaner fuel as compared to continuing biomass smoke exposure and observed more than a
$50 \%$ decrease in the risk of developing COPD [48].

Indoor levels of carbon monoxide (CO), sulphur dioxide $\left(\mathrm{SO}_{2}\right)$, and nitric oxide $(\mathrm{NO})$ during cooking and 3 hours thereafter were measured in 50 randomly chosen participant households. The levels of all these compounds were unacceptably high (peak CO: 999 parts per million [ppm], with a time-weighted average [TWA] of $596 \mathrm{ppm}$; peak $\mathrm{SO}_{2}: 99.9 \mathrm{ppm}$, with a TWA of $23.4 \mathrm{ppm}$; peak NO level: 38.3 ppm, with a TWA of $5.7 \mathrm{ppm}$ ). At 3 hours, the levels of $\mathrm{CO}, \mathrm{SO}_{2}$, and $\mathrm{NO}$ remained unacceptably high at 37,15 , and $4 \mathrm{ppm}$, respectively (manuscript under preparation).

Of the 1,085 constituent members of the cohort, 9 of the 915 men $(1.0 \%)$ and 1 of the 170 women $(0.6 \%)$ were diagnosed with COPD. The most common abnormality on spirometry in both gender was a restrictive defect (40.0\%), and this was significantly more common among women than among men in those aged less than 40 years ( $28.0 \%$ of men vs. $43.0 \%$ in women). The prevalence of asthma confirmed by spirometry was $6.9 \%$ (75 of 1,085) in our study (manuscript under preparation).

At the 5-year follow-up, 72 of the 573 participants (12.6\%) with chronic bronchitis and 17 of the 296 participants (5.7\%) without chronic bronchitis had died, indicating a much higher all-cause 5 -year mortality rate in those with chronic bronchitis (manuscript under preparation).

The nested case-control study $(\mathrm{n}=98)$ identified the chemokines chemokine (C-C motif) ligand (CCL)20, CCL27, and chemokine (C$\mathrm{X}-\mathrm{C}$ motif) ligand (CXCL) 13 as putative, plausibly homeostatic biomarkers for biomass smoke-induced COPD. Ten cytokines and chemokines exhibited higher concentrations in the tobacco smokeexposed controls than in the tobacco smoke-exposed COPD cases. A comparison of cytokine and chemokine concentrations between the biomass smoke-induced COPD subjects and the tobacco smoke-induced COPD subjects and the corresponding subjects who were exposed to biomass smoke or tobacco smoke but did not develop COPD also revealed distinct molecular profiles [49] (manuscript submitted).

\section{STRENGTHS AND WEAKNESSES}

The main strength of the MUDHRA cohort is that it is population-based and representative of the rural population in southern India. This is the single largest rural cohort in India in which all participants underwent standardized assessments for the diagnosis of COPD according to ATS criteria, with a repeat assessment for lung function at a 5-year follow-up. Very few declined to participate at baseline $(<5 \%)$ and in the follow-up studies $(<7 \%)$. We measured $\mathrm{CO}, \mathrm{SO}_{2}$ and $\mathrm{NO}$ in a subset of households. Particulate matter levels $\left(\mathrm{PM}_{2.5}, \mathrm{PM}_{10}\right)$ were not measured. Participants were not examined for cardio-metabolic disorders. Although allcause mortality was reported for the cohort at the 5-year followup, the cause of death was not ascertained. We intend to overcome this by establishing the probable cause of death by conducting a standardised verbal autopsy interview with a reliable informant of the deceased and recording the cause of death from medical records or the death certificate. 


\section{DATA ACCESSIBILITY}

The study data are not freely available, but the MUDHRA cohort team would welcome collaborations with other researchers. For further information, contact Dr. Mahesh PA based at JSS Medical College, JSS Academy of Higher Education and Research, Mysuru, India (mahesh1971in@yahoo.com).

\section{ACKNOWLEDGEMENTS}

We sincerely acknowledge the subjects for their kind consent and cooperation. We also thank the Principal, JSS Medical College, JSS Academy of Higher Education and Research, field staff Sathish Chandran M, Raju M (spirometry technicians), Shobha (lab technician), and Lingambika (data entry), who assisted in field and lab work and the grama panchayat members for their coordination. We also thank Dr. AK Prabhakar, Senior Epidemiologist, and Dr. MVSST Subba Rao, Associate Professor of Biochemistry from JSS Academy of Higher Education and Research, and Dr. S Ravi, Professor of Statistics from Mysore University for their valuable input.

This work was supported by the Indian Council of Medical Research (ICMR), India (grant no. 5/8/4-4[Env]/2003-NCD-I [20062011]); National Institutes of Health (NIH) Fogarty International Center (FIC) Global Health Equity Scholars (GHES) USA, (R25 TW009338, D43 TW010540) and the systemic biomarkers analysis by grants DBT-India (BT/PR12987/INF/22/205/2015 and VINNOVA [2016-01951] to K.G). The funding agency had no say in the conduct of the study, design of the study, analysis of the data and writing the manuscript.

\section{CONFLICT OF INTEREST}

The authors have no conflicts of interest to declare for this study.

\section{ORCID}

Padukudru Anand Mahesh: https://orcid.org/0000-0003-16325945; Komarla Sundararaja Lokesh: https://orcid.org/0000-00015651-1123; Purnima Madhivanan: https://orcid.org/0000-00017818-3394; Sindaghatta Krishnarao Chaya: https://orcid.org/00000002-4898-9466; Biligere Siddaiah Jayaraj: https://orcid.org/00000001-6055-4580; Koustav Ganguly: https://orcid.org/0000-0001$8531-8154$

\section{REFERENCES}

1. GBD 2015 Chronic Respiratory Disease Collaborators. Global, regional, and national deaths, prevalence, disability-adjusted life years, and years lived with disability for chronic obstructive pulmonary disease and asthma, 1990-2015: a systematic analysis for the Global Burden of Disease Study 2015. Lancet Respir Med 2017;5:691-706.
2. Vogelmeier CF, Criner GJ, Martinez FJ, Anzueto A, Barnes PJ, Bourbeau J, et al. Global strategy for the diagnosis, management, and prevention of chronic obstructive lung disease 2017 report. GOLD executive summary. Am J Respir Crit Care Med 2017;195:557-582.

3. World Health Organization. Global status report on noncommunicable diseases 2010; 2011 [cited 2018 Jul 4]. Available from: http://www.who.int/nmh/publications/ncd_report2010/en/.

4. India State-Level Disease Burden Initiative Collaborators. Nations within a nation: variations in epidemiological transition across the states of India, 1990-2016 in the Global Burden of Disease Study. Lancet 2017;390:2437-2460.

5. McKay AJ, Mahesh PA, Fordham JZ, Majeed A. Prevalence of COPD in India: a systematic review. Prim Care Respir J 2012;21: 313-321.

6. Salvi SS, Barnes PJ. Chronic obstructive pulmonary disease in non-smokers. Lancet 2009;374:733-743.

7. Ministry of Home Affairs, Government of India. Census data online-2001 [cited 2018 Apr 5]. Available from: http://www.censusindia.gov.in/2011-common/censusdataonline.html.

8. Mahesh PA, Jayaraj BS, Prahlad ST, Chaya SK, Prabhakar AK, Agarwal AN, et al. Validation of a structured questionnaire for COPD and prevalence of COPD in rural area of Mysore: a pilot study. Lung India 2009;26:63-69.

9. Jindal SK, Aggarwal AN, Chaudhry K, Chhabra SK, D’Souza GA, Gupta D, et al. A multicentric study on epidemiology of chronic obstructive pulmonary disease and its relationship with tobacco smoking and environmental tobacco smoke exposure. Indian J Chest Dis Allied Sci 2006;48:23-29.

10. Sousa RM, Ferri CP, Acosta D, Albanese E, Guerra M, Huang Y, et al. Contribution of chronic diseases to disability in elderly people in countries with low and middle incomes: a 10/66 Dementia Research Group population-based survey. Lancet 2009;374:18211830.

11. Medhi GK, Hazarika NC, Borah PK, Mahanta J. Health problems and disability of elderly individuals in two population groups from same geographical location. J Assoc Physicians India 2006; 54:539-544.

12. Goel S, Gupta BP, Kashyap S, Bhardwaj AK. Epidemiological aspects of chronic bronchitis in Shimla hills. Indian J Chest Dis Allied Sci 2007;49:143-147.

13. Chhabra SK, Chhabra P, Rajpal S, Gupta RK. Ambient air pollution and chronic respiratory morbidity in Delhi. Arch Environ Health 2001;56:58-64.

14. Joshi K, Kumar R, Avasthi A. Morbidity profile and its relationship with disability and psychological distress among elderly people in Northern India. Int J Epidemiol 2003;32:978-987.

15. Qureshi KA. Domestic smoke pollution and prevalence of chronic bronchitis/asthma in a rural area of Kashmir. Indian J Chest Dis Allied Sci 1994;36:61-72.

16. Nigam P, Verma BL, Srivastava RN. Chronic bronchitis in an Indian rural community. J Assoc Physicians India 1982;30:277-280.

17. Mukherjee R, Moore VC, Purkait S, Goon P, Warburton CJ, Chakrabarti B, et al. P121. Feasibility of performing valid spirom- 
etry in rural India: preliminary results from a population study assessing the prevalence of COPD. Thorax 2010;65(Suppl 4): A129.

18. Akhtar MA, Latif PA. Prevalence of chronic bronchitis in urban population of Kashmir. J Indian Medl Assoc 1999;97:365-366.

19. Jindal SK. A field study on follow up at 10 years of prevalence of chronic obstructive pulmonary disease \& peak expiratory flow rate. Indian J Med Res 1993;98:20-26.

20. Kamat SR, Doshi VB. Sequential health effect study in relation to air pollution in Bombay, India. Eur J Epidemiol 1987;3:265-277.

21. Ray D, Abel R, Selvaraj KG. A 5-yr prospective epidemiological study of chronic obstructive pulmonary disease in rural south India. Indian J Med Res 1995;101:238-244.

22. Malik SK, Kashyap S. Chronic bronchitis in rural hills of Himachal Pradesh, northern India. Indian J Chest Dis Allied Sci 1986;28:70-75.

23. Malik SK, Banga N, Qamra S. Chronic bronchitis in Chandigarh, North India. Bull Postgrad Inst Med Educ Res (Chandigarh) 1981:15:161-163.

24. Bailey KL, Goraya J, Rennard SL. The role of systemic inflammation in COPD. In: Nici L., ZuWallack R, editors. Chronic obstructive pulmonary disease. Totowa: Humana Press; 2012, p. 15-30.

25. Agustí AG, Noguera A, Sauleda J, Sala E, Pons J, Busquets X. Systemic effects of chronic obstructive pulmonary disease. Eur Respir J 2003;21:347-360.

26. Singh D, Edwards L, Tal-Singer R, Rennard S. Sputum neutrophils as a biomarker in COPD: findings from the ECLIPSE study. Respir Res 2010;11:77.

27. Roy K, Smith J, Kolsum U, Borrill Z, Vestbo J, Singh D. COPD phenotype description using principal components analysis. Respir Res 2009;10:41.

28. Vernooy JH, Küçükaycan M, Jacobs JA, Chavannes NH, Buurman WA, Dentener MA, et al. Local and systemic inflammation in patients with chronic obstructive pulmonary disease: soluble tumor necrosis factor receptors are increased in sputum. Am J Respir Crit Care Med 2002;166:1218-1224.

29. Camp PG, Ramirez-Venegas A, Sansores RH, Alva LF, McDougall JE, Sin DD, et al. COPD phenotypes in biomass smoke- versus tobacco smoke-exposed Mexican women. Eur Respir J 2014; 43:725-734.

30. Buist AS, Vollmer WM, Sullivan SD, Weiss KB, Lee TA, Menezes AM, et al. The burden of obstructive lung disease initiative (BOLD): rationale and design. COPD 2005;2:277-283.

31. Miller MR, Hankinson J, Brusasco V, Burgos F, Casaburi R, Coates A, et al. Standardisation of spirometry. Eur Respir J 2005;26:319-338.

32. Heatherton TF, Kozlowski LT, Frecker RC, Fagerström KO. The Fagerström test for nicotine dependence: a revision of the Fagerström Tolerance Questionnaire. Br J Addict 1991;86:1119-1127.

33. Jones PW, Harding G, Berry P, Wiklund I, Chen WH, Kline Leidy N. Development and first validation of the COPD Assessment Test. Eur Respir J 2009;34:648-654.

34. Meguro M, Barley EA, Spencer S, Jones PW. Development and validation of an improved, COPD-specific version of the St. George Respiratory Questionnaire. Chest 2007;132:456-463.

35. Mahler DA, Wells CK. Evaluation of clinical methods for rating dyspnea. Chest 1988;93:580-586.

36. ATS Committee on Proficiency Standards for Clinical Pulmonary Function Laboratories. ATS statement: guidelines for the six-minute walk test. Am J Respir Crit Care Med 2002;166:111117.

37. Hamilton M. The assessment of anxiety states by rating. Br J Med Psychol 1959;32:50-55.

38. Hamilton M. A rating scale for depression. J Neurol Neurosurg Psychiatry 1960;23:56-62.

39. Thimraj TA, Vishweswaraiah S, Chaya SK, Lokesh KS, Jayaraj BS, Ganguly K, et al. Comparison of serum cytokine profiles among biomass-and tobacco smoke induced chronic obstructive pulmonary disease (COPD) patients in a South Indian population: a pilot study. Eur Respir J 2017;50: PA420.

40. Global Initiative for Asthma. 2017 GINA report: global strategy for asthma management and prevention [cited 2018 Feb 1]. Available from: https:/ginasthma.org/gina-reports/.

41. Mahesh PA, Jayaraj BS, Prabhakar AK, Chaya SK, Vijayasimha R. Prevalence of chronic cough, chronic phlegm \& associated factors in Mysore, Karnataka, India. Indian J Med Res 2011;134:91100.

42. Mahesh PA, Jayaraj BS, Prabhakar AK, Chaya SK, Vijaysimha R. Identification of a threshold for biomass exposure index for chronic bronchitis in rural women of Mysore district, Karnataka, India. Indian J Med Res 2013;137:87-94.

43. Mahesh PA, Jayaraj BS, Chaya SK, Lokesh KS, McKay AJ, Prabhakar AK, et al. Variation in the prevalence of chronic bronchitis among smokers: a cross-sectional study. Int J Tuberc Lung Dis 2014;18:862-869.

44. Behera D, Jindal SK. Respiratory symptoms in Indian women using domestic cooking fuels. Chest 1991;100:385-388.

45. Hu G, Zhou Y, Tian J, Yao W, Li J, Li B, et al. Risk of COPD from exposure to biomass smoke: a metaanalysis. Chest 2010;138:2031.

46. Salvi S, Barnes PJ. Is exposure to biomass smoke the biggest risk factor for COPD globally? Chest 2010;138:3-6.

47. Mahmood T, Singh RK, Kant S, Shukla AD, Chandra A, Srivastava RK. Prevalence and etiological profile of chronic obstructive pulmonary disease in nonsmokers. Lung India 2017;34:122-126.

48. Zhou Y, Zou Y, Li X, Chen S, Zhao Z, He F, et al. Lung function and incidence of chronic obstructive pulmonary disease after improved cooking fuels and kitchen ventilation: a 9-year prospective cohort study. PLoS Med 2014;11:e1001621.

49. Vishweswaraiah S, Thimraj T, George L, Chaya SK, Lokesh KS, Jayaraj BS, et al. Putative systemic biomarkers of biomass smoke induced chronic obstructive pulmonary disease (COPD) in a South Indian population: a pilot study. In: Proceedings of Society of Toxicology 57th Annual Meeting and ToxExpo; 2018 Mar 1115; San Antonio, USA. Reston: American Society for Toxicology; 2018, p. 115. 